\title{
Sewer overflow in the urban model MURI
}

\author{
Tariq Chibane ${ }^{1, *},{ }^{2}$, André Paquier ${ }^{1}$, Saâdia Benmamer $^{2}$, and Cécile Lalanne ${ }^{1}$ \\ ${ }^{1}$ Irstea, UR RiverLy, 5 rue de la Doua, CS 20244, 69625 Villeurbanne, France \\ ${ }^{2}$ Ecole Nationale Polytechnique d'Alger, LRS-EAU, 10 Avenue Hassen Badi, BP 182, El Harrach, \\ 16200 Algérie
}

\begin{abstract}
Sewer overflow is one of the main causes of urban floods. Using an urban model called MURI recently built by Irstea, a series of experiments are carried out in order to simulate overflowing cases. The first configuration that was studied is a single street of $5.4 \mathrm{~m}$ in length, $0.15 \mathrm{~m}$ in width with a slope of $0.1 \%$ and two street inlets (of which the orifice diameter is $14 \mathrm{~mm}$ ) that ensure the connection with the sewer network. Inflows of 2 and $3 \mathrm{~L} / \mathrm{s}$ are used for the street and an inflow of 0.5 $\mathrm{L} / \mathrm{s}$ for the sewer network that is partially closed in order to obtain overflow at the street inlets. The rising of the weir downstream the street permitted to obtain same water depth and to measure the vertical profiles of velocities. This study allowed us to investigate how the overflow process influence the water depth and the velocity field around the street inlet. The exchange flow discharge can be calculated using either an orifice equation or the head loss in the two pipes connecting the street and the sewage network, both methods requesting calibration, which is made difficult by the complexity of the flow around the street inlets.
\end{abstract}

\section{Introduction}

Floods are one of the main natural hazards in the world and cause a lot of damages on urban areas. In an urban flood, interaction between surface runoff and flow into the sewer system can take place. Considering this interaction is necessary to understand the phenomenon of urban flooding. In order to investigate flows and to properly understand and describe the exchange of flows between the streets and the sewer network during floods event, an urban model called MURI was built at Irstea Hydraulics Laboratory (HH Lab). It represents a city area with its sewer network and permits to carry out experiments to understand the processes and to validate the numerical simulations.

Going through scientific papers, one can find some studies dealing with the efficiency of street inlets draining the street including detailed 3D calculation of the flow [1]. However, the exchange processes due to overflow have seldom been studied [2]. Generally, the exchange discharges are calculated applying a simple orifice equation. Experiments using MURI in a simple configuration (one street and one pipe) allow investigating the

\footnotetext{
* Corresponding author: tariq.chibane@irstea.fr
} 
interaction between the flow into the sewer network and the street runoff during this overflow process.

The paper starts by a description of the facility and of the experimental runs. Then results of the measurements (water depths and velocities) are presented, analyzed and discussed focusing on the differences between the two flows and the calculation of the exchange flow discharge.

\section{Experimental features}

\subsection{Description of the model MURI}

The Urban Model for the Study of Flood Risk (MURI) includes two floors. Floor 2 is a rectangular PVC tray of 3.8 by 5.4 m representing flooded streets. Figure 1 shows this floor set in the initial configuration including a pattern of 3 streets in $x$ and $y$ directions. All the streets are $15 \mathrm{~cm}$ wide and limited by $15 \mathrm{~cm}$ high transparent PETG sheets. The slope of the tray can be fixed in both directions, longitudinal and transverse from 0 to $5 \%$. A maximum inflow of $50 \mathrm{~L} / \mathrm{s}$ can be sent to the streets. This flow can enter or exit the model through small tanks of which the dimensions are $0.3 \mathrm{~m} \times 0.5 \mathrm{~m} \times 0.5 \mathrm{~m}$. At inflow, a honeycomb is set up to have a stable flow while a downstream weir can control the downstream water level.

The first floor is a network of transparent PVC pipes fixed to a metal structure set about $0.3 \mathrm{~m}$ below the second floor and in which an inflow up to $5 \mathrm{~L} / \mathrm{s}$ can be sent directly. The main collector has a diameter of about $0.1 \mathrm{~m}$ while the secondary pipes have a diameter of about $0.05 \mathrm{~m}$. These pipes are connected to the second floor by small pipes (diameter equal to $19 \mathrm{~mm}$ reducing to $14 \mathrm{~mm}$ at the connection devices) that have different lengths depending on the availability of an easy junction to the sewer network.

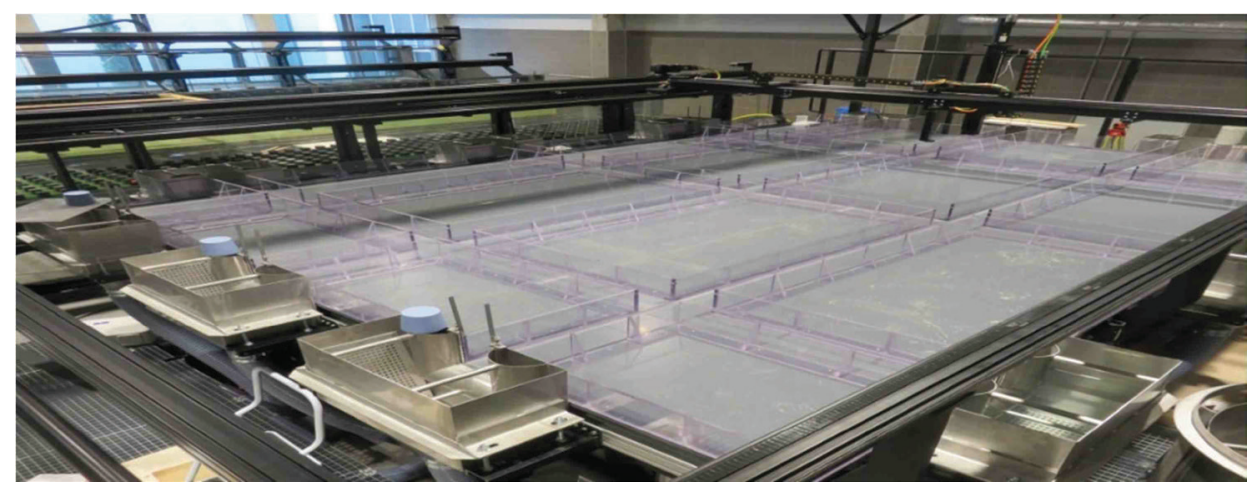

Fig. 1. General view of the urban model MURI

A series of preliminary experiments were carried out in order to check the facility and the calibration of the various devices. At first, using an ultrasonic sensor (US), the topography of the second floor was determined in order to be able to obtain a reliable value of the water depth from the measurement of the water level. In a second time, various simple configurations with various flow regimes permitted to estimate the real roughness of the material (PVC) for the surface and the sewer network. Using Darcy-Weisbach and Manning-Strickler equations, the calibration results agree with process based values (size of roughness of about $0.1 \mathrm{~mm}$ and Strickler coefficients of $120 \mathrm{~m}^{1 / 3} / \mathrm{s}$ in the streets and 109 $\mathrm{m}^{1 / 3} / \mathrm{s}$ in the pipes but in the sewer network, local head losses due to the pipes junctions 
should be added. At the same time, the discharges were measured using flowmeters at the upstream and the downstream of the model; a slight measurement bias (1\%) was observed between flowmeters because of the air entrainment or other cause.

\subsection{Measurement devices}

The water level and velocity in the streets are measured using an Ultrasonic Sensor (US) and an Acoustic Doppler Velocimeter (ADV) respectively, these devices being mounted on a sliding gantry that is controlled by a LabVIEW program. The supplier of the US indicates a standard error less than $0.3 \mathrm{~mm}$; the measurement is made on a disk about $10 \mathrm{~mm}$ in diameter around the desired point and averaged over a period of $\Delta \mathrm{t}=30 \mathrm{~s}$. The side-looking Vectrino ADV measures the velocity in a volume of diameter $6.6 \mathrm{~mm}$ and length adjustable from 3 to $15 \mathrm{~mm}$, offset by $55 \mathrm{~mm}$ on the side compared to the transmitter. To obtain reliable data, defined by a ratio signal/noise SNR greater than or equal to 20, it is necessary to seed the flow with particles, using a system composed of a peristaltic pump and a stirrer. During experiments, a convergence time equal to 200 seconds is used. To check that the ADV is aligned with the model, the velocity $V_{y}$ at a wall of a street is measured and a rotation matrix is applied to all the measurements in order that the transverse velocity is null at the wall.

\subsection{Overflow experiments}

Investigating overflow processes only, one single street was used (Figure 2), the connections with the other streets closed using PVC plates.
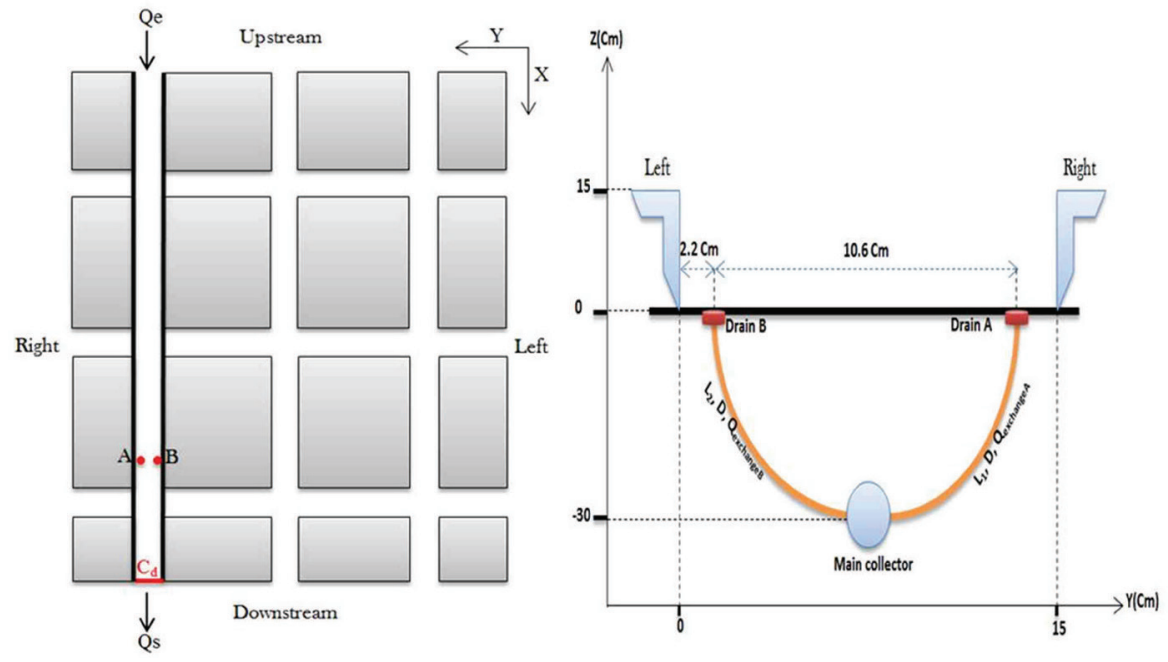

Fig. 2. Plane view of MURI second floor and cross section of the drainage system.

The streamwise slope was fixed to $0.1 \%$. At the level of the sewer network, the secondary pipes were isolated, so that water flows only in the main collector that was connected at two points with the street. The inflow $Q_{e}$ in the street (5.4 m long ( $X$-axis with zero value at the upstream end) and $0.15 \mathrm{~m}$ wide prismatic channel) was measured using the flowmeter D203. The outflow $Q_{s}$ was measured by the flowmeter D212. $C_{d}$ was the weir height downstream, set at $5 \mathrm{~cm}$ for the inflow of $2 \mathrm{~L} / \mathrm{s}$ and at $4 \mathrm{~cm}$ for the inflow of $3 \mathrm{~L} / \mathrm{s}$ in order to get the same water depth at drain location. The inflow $Q_{r}$ into the main pipe set to $0.5 \mathrm{~L} / \mathrm{s}$ 
was measured by the flowmeter D101, the outflow of the pipe $Q_{o}$ being measured by the flowmeter D112.

\section{Experiments results}

\subsection{Main features and reference measurements}

First, experiments were carried out without connection between the streets and the pipes. Hydraulics parameters for these experiments are shown in table 1.

Table 1. Hydraulic parameters of the experiments (at $x=3930 \mathrm{~mm}$ I.E. $200 \mathrm{~mm}$ upstream from the drains location).

\begin{tabular}{|l|l|l|l|l|l|l|l|}
\hline Case & $\begin{array}{l}Q_{e} \\
\left(\mathrm{~m}^{3} / \mathrm{s}\right)\end{array}$ & $\begin{array}{l}\text { Water } \\
\text { depth }(\mathrm{m})\end{array}$ & $\begin{array}{l}\text { Wetted } \\
\text { area }\left(\mathrm{m}^{2}\right)\end{array}$ & $\begin{array}{l}\text { Wetted } \\
\text { perimeter } \\
(\mathrm{m})\end{array}$ & $\begin{array}{l}\text { Velocity } \\
(\mathrm{m} / \mathrm{s})\end{array}$ & Froude & Reynolds \\
\hline 1 & 0.002 & 0.082 & 0.0123 & 0.314 & 0.16 & 0.18 & 12651 \\
\hline 2 & 0.003 & 0.082 & 0.0123 & 0.314 & 0.24 & 0.27 & 18975 \\
\hline
\end{tabular}

In the street using the US, the water level was measured along the street for three profiles, the first one at the middle of the street and the other ones above the two drains A and B (noted line A and line B). The space step is $\Delta x=100 \mathrm{~mm}$. Along these lines, 10 vertical profiles of the mean flow velocities were also measured with a space step of $500 \mathrm{~mm}$ between two profiles. Moreover, five additional profiles are measured around the location of the drain with a space step of about $50 \mathrm{~mm}$.

Second, after connection with the sewer network and establishment of a steady inflow of $0.5 \mathrm{~L} / \mathrm{s}$ in the main collector with an outlet valve opened at $24 \%$, the same measurements are performed in a situation in which an overflow is occurring at the two holes A and B.

\subsection{Water elevation and velocity measurements}

\subsubsection{Water depth}

Figure 3 shows the water line calculated averaging the three profiles.

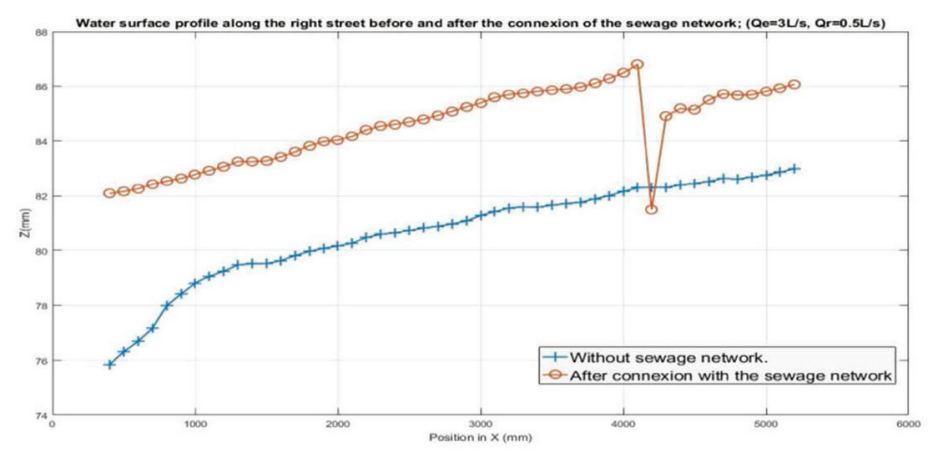

Fig. 3. Water depth along the street before and after the opening of the sewer network $\left(Q_{e}=3 \mathrm{~L} / \mathrm{s}\right.$, $\left.Q_{r}=0.5 \mathrm{~L} / \mathrm{s}\right)$ 
After the opening of the drains, because of the increase of the discharge in the downstream part of the street, the water depth rises downstream. Because the flow is subcritical, the head losses at the drains make this rise higher upstream (up to $5 \mathrm{~mm}$ at the drains location).

\subsubsection{Velocities}

Figure 4 shows the development in the $X$ direction of the vertical profile of the longitudinal velocity in the middle of the street. The upstream disturbance due to the arrival by a tank is more pronounced for the case without connection but for this latter case, the profile is stabilized in the downstream part of the street. In case of overflow, the increase of the velocity near the bottom is marked at the drains location, propagates to the surface with transverse rearrangement of the flow and then turns back to the bottom.
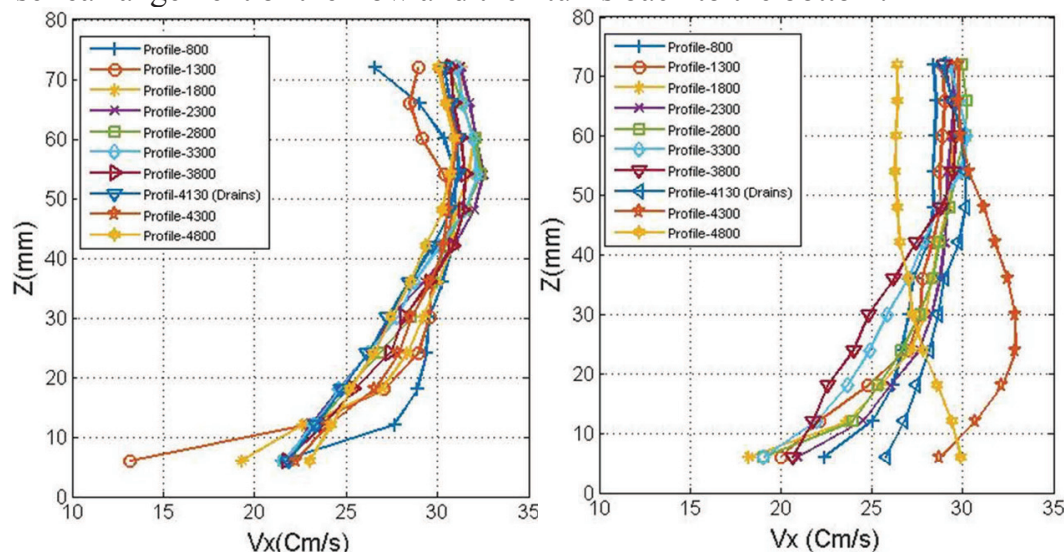

Fig. 4. Vertical profiles of the mean flow longitudinal velocities along the middle of the street; $Q_{e}=3$ $\mathrm{L} / \mathrm{s}$ : left $=$ without connection, right $=$ with outflow .

Figure 5 of the transverse velocity in case of overflow shows opposite directions of flow near the bottom and at surface, sign of a secondary flow agreeing with a dipping of water in the street centre. The bottom velocity is oriented from drain B to drain A (smaller outflow). Without connection, the transverse velocity profile is slightly perturbed revealing that neither upstream inflow nor closing of adjacent streets are perfect.
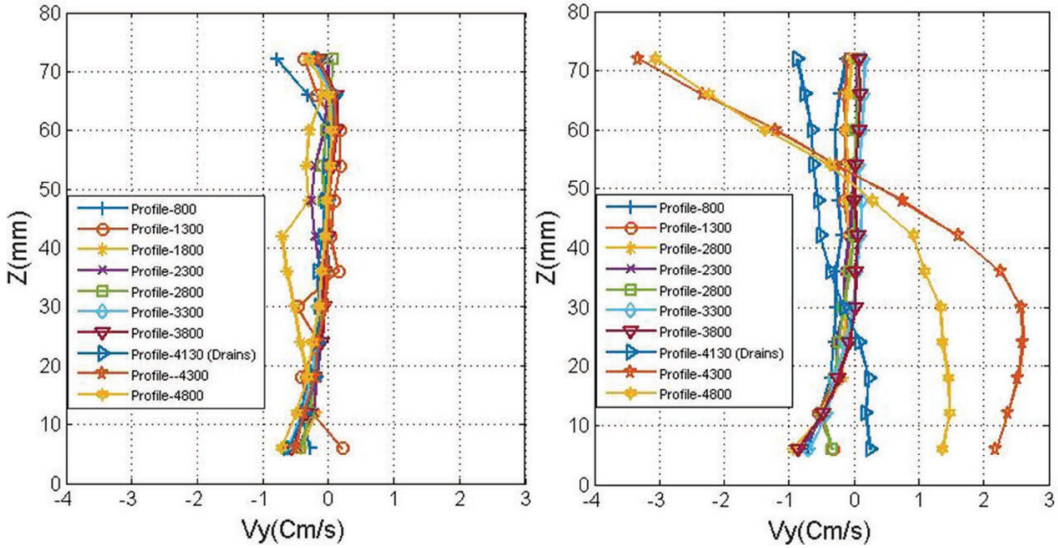

Fig. 5. Vertical profiles of the mean flow transverse velocities along the middle of the street; $Q_{e}=3$ $\mathrm{L} / \mathrm{s}$ : left $=$ without connection, right $=$ with outflow. 

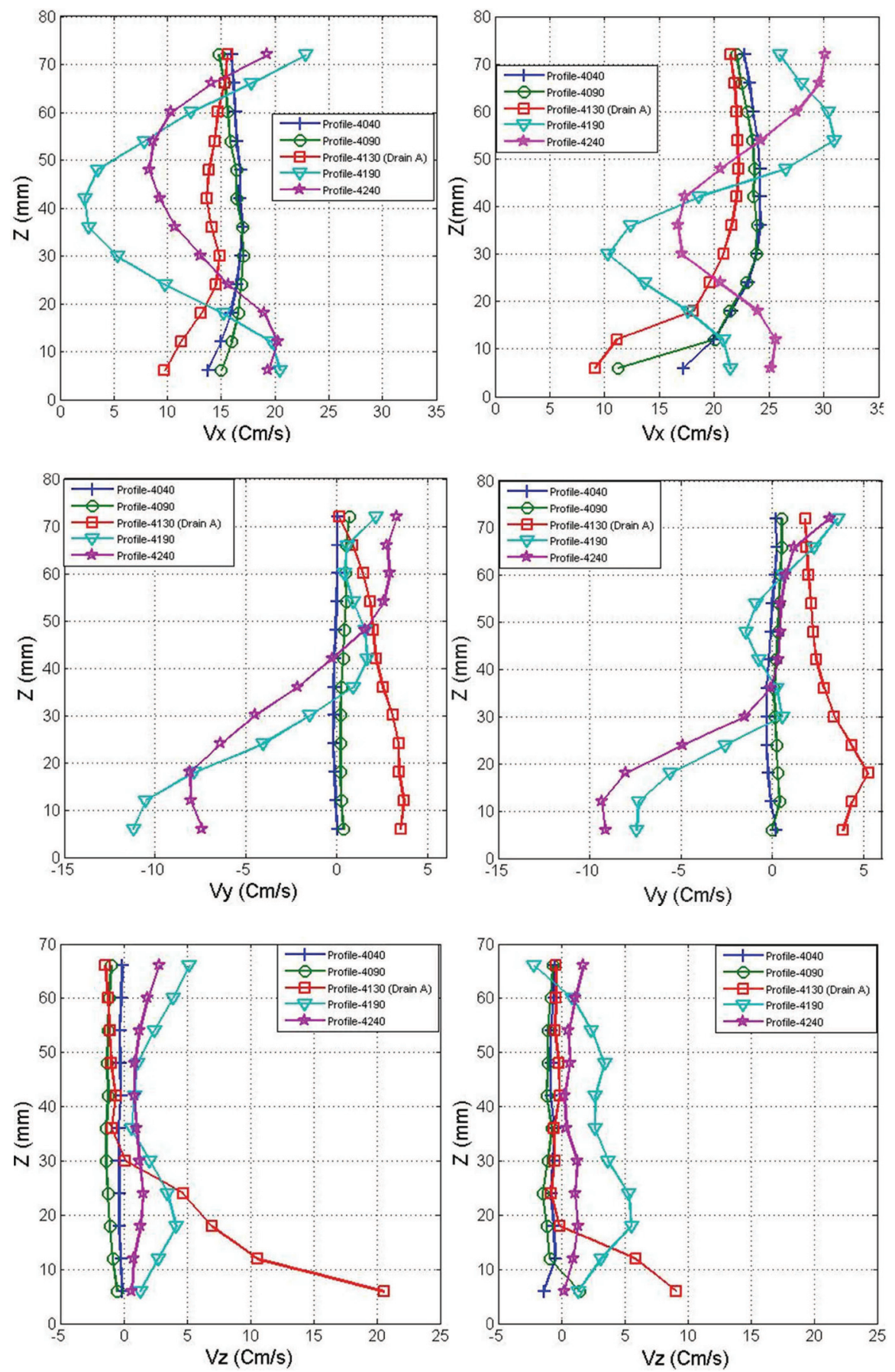

Fig. 6. Vertical profiles of longitudinal, transverse and vertical velocities around the drain (line A) in case of overflow; left: $Q_{e}=2 \mathrm{~L} / \mathrm{s}$, right: $Q_{e}=3 \mathrm{~L} / \mathrm{s}$

Figure 6 shows that the two cases are quite similar near the drain: particularly, near the bottom, a lower longitudinal velocity and a vertical velocity, a transverse velocity to the wall, all features due to the water coming out vertically from the sewer network. But the 
bottom vertical velocity is much higher for the lower flow while the other effects are lower. Downstream from the drains, one can note an acceleration of the flow at the bottom with an important transverse velocity to the middle of the street at the bottom; for the longitudinal velocity, both cases show higher velocities at bottom and at surface but at mid depth the decrease of velocity is much higher for the lower inflow putting forward the higher flow blockage by the overflow.

\section{Flow exchanges}

Table 2 shows the measured discharges for the case $2\left(Q_{e}=3 \mathrm{~L} / \mathrm{s}, Q_{r}=0.5 \mathrm{~L} / \mathrm{s}\right)$.

Table 2. Average discharge measurements after the opening of drains A and B.

\begin{tabular}{|c|c|c|c|c|}
\hline Flowmeters & Duration (s) & $\begin{array}{c}\text { Average } \\
\text { discharges } \\
(\mathrm{L} / \mathrm{s})\end{array}$ & $\begin{array}{c}\text { Standard } \\
\text { deviation } \\
(\mathrm{L} / \mathrm{s})\end{array}$ & $\begin{array}{c}\text { (D203+ D103) - } \\
\text { (D212+D112) } \\
(\mathrm{L} / \mathrm{s})\end{array}$ \\
\hline D203 & 4410 & 2.95 & 0.016 & -0.04 \\
\cline { 1 - 2 } D212 & 4410 & 3.29 & 0.020 & \\
\hline D103 & 4410 & 0.52 & 0.009 & \\
\hline D112 & 4410 & 0.22 & 0.006 & \\
\hline
\end{tabular}

The average flow discharge from the sewer network to the surface is about $0.32 \mathrm{~L} / \mathrm{s}$ with an uncertainty of about $0.04 \mathrm{~L} / \mathrm{s}$. For the case $1\left(Q_{e}=2 \mathrm{~L} / \mathrm{s}, Q_{r}=0.5 \mathrm{~L} / \mathrm{s}\right)$, results are quite the same ones.

In such a case of overflow, [2] shows that an accurate calculation of the exchange discharge should pass by the estimate of the head losses along the connecting devices and that the estimate using an orifice equation cannot be enough, the resulting discharge coefficient varying between 0.39 and 0.46 and being far from the classical value of 0.6.

In order to check this latter result, two simple estimates of the exchange discharge were performed for case 2. Pressure in the pipe (measured by a piezometer) was $0.26 \mathrm{~m}$ (above the reference level of the second floor) while the water head in the street was $0.09 \mathrm{~m}$. Using the orifice equation and a diameter of $0.014 \mathrm{~m}$ (the one at the inlet and at the outlet of the connection pipe) with the classical discharge coefficient of 0.6 provides a discharge of 0.34 $\mathrm{L} / \mathrm{s}$ (for two drains), which is a fair estimate. If the flow is calculated using a singular head loss with a coefficient of 1.5 (at the inlet and outlet of diameter $0.014 \mathrm{~m}$ ) and a linear loss along the connecting pipe of diameter $0.019 \mathrm{~m}$, the discharges are respectively $0.26 \mathrm{~L} / \mathrm{s}$ for drain $\mathrm{A}$ and $0.28 \mathrm{~L} / \mathrm{s}$ for drain $\mathrm{B}$ (shorter connecting pipe), which is much too high and means that the singular head losses are much higher than provided using the value of 1.5 because of the diameter change and the flow disturbance at the outflow in the street. Of course, calculations and results are similar for case 1 .

\section{Conclusions}

Experiments were performed on the model MURI, for a configuration of one street with a longitudinal slope of $0.1 \%$ and two drains connected to a pipe to ensure an outflow from the pipe to the street.

The outflow discharge is fairly estimated using an orifice equation despite the complexity of the flow along the connecting devices and at the outflow locations.

In the street, the outflow creates a blockage for the upstream flow that is obliged to pass beside and above the outflow. The downstream rearrangement of the flow creates 
secondary flows in the whole cross section that are dissipating slowly, the latter process being not finished at the downstream end of the street.

This research is supported by the exchange research program CMEP-Tassili between Algeria and France.

\section{References}

1 . S. Djordjevic, A. J. Saul, G. R. Tabor, J. Blanksby, I. Galambos, N. Sabtu, G. Sailor. Water Science and Technology, 67, 3, 535-542 (2013).

2 . P. H. Bazin, H. Nakagawa, K. Kawaike, A. Paquier, E. Mignot. Journal of Hydraulic Engineering-ASCE, 140, DOI: 10.1061/(ASCE)HY.1943-7900.0000917, (2014). 